\title{
Modificações na população de plantas espontâneas na presença de adubos verdes ${ }^{(1)}$
}

\author{
Claudenir Favero(2), Ivo Jucksch ${ }^{(2)}$, Ramon Costa Alvarenga ${ }^{(3)}$ e Liovando Marciano da Costa(2)
}

Resumo - A adubação verde pode provocar modificações na população de plantas espontâneas devido aos efeitos alelopáticos e à competição por luz, água, oxigênio e nutrientes, acarretando supressão de algumas delas. Por outro lado, as leguminosas, pelas melhorias que promovem nas condições do solo, favorecem espécies com maior capacidade de ciclagem de nutrientes e produção de biomassa. O objetivo deste trabalho foi avaliar as modificações na população de plantas espontâneas por leguminosas usadas como adubo verde. O experimento foi realizado em Sete Lagoas, MG na Embrapa-Centro Nacional de Pesquisa de Milho e Sorgo. O solo local é um Latossolo Vermelho distrófico típico, e o clima, do tipo Aw (tropical estacional de savana). O experimento consistiu de seis tratamentos, sendo cinco espécies de leguminosas (feijão-de-porco, feijão-bravo-do-ceará, mucuna-preta, lab-lab e guandu), cultivadas na presença de plantas espontâneas, e a testemunha (solo preparado e deixado em pousio com as plantas espontâneas), e as leguminosas, cultivadas em dois anos agrícolas. O feijão-bravo-doceará, seguido da mucuna-preta e do feijão-de-porco, foram as leguminosas com maiores produtividades de biomassa. A mucuna-preta demonstrou maior potencial para cobertura do solo e supressão de plantas espontâneas. $\mathrm{O}$ uso de leguminosas para adubação verde promove modificações na dinâmica de sucessão das espécies espontâneas.

Termos para indexação: plantas daninhas, plantas de cobertura, leguminosas, cobertura vegetal.

\section{Modifications in the population of spontaneous plants in the presence of green manure}

\begin{abstract}
Green manure can cause modifications in the population of spontaneous plants (weeds) due to allelopatic effects and competition for light, water, oxygen and nutrients, with the possibility of eliminating some of them. On the other hand, legume crops may favor species with higher capacity of nutrients cycling and biomass production, due to improvements that they promote in the soil conditions. The objective of this work was to evaluate the alteration in the number of spontaneous crops by legume crops used as green manure. The experiment was carried out in Sete Lagoas, MG, Brazil, at Embrapa-Centro Nacional de Pesquisa de Milho e Sorgo in a typical dystrophic Latosol under Aw (seasonal tropical Savannah) climate. The experiment consisted of six treatments, five of which were legume crops jack bean, "feijão-bravo", mucuna, lab-lab and pigeonpea grown together with spontaneous plants, and one was the witness treatment (only plowed soil and fallow), with the legumes being cropped for two years. "Feijão-bravo", mucuna and jack bean were the legumes with highest biomass yield. Mucuna is the species of cover plant with the highest potential for soil coverage and suppression of spontaneous crops. The use of legumes as green manure promotes modifications in the sequential dynamics of spontaneous species.
\end{abstract}

Index terms: weeds, cover plants, legumes, plant cover.

(1)Aceito para publicação em 11 de dezembro de 2000. Extraído da Dissertação de Mestrado apresentada pelo primeiro autor à Universidade Federal de Viçosa (UFV), Viçosa, MG

(2)UFV, Dep. de Solos, CEP 36571-000 Viçosa, MG. E-mail: clf@solos.ufv.br, ivo@solos.ufv.br, liovando@solos.ufv.br

(3)Embrapa-Centro Nacional de Pesquisa de Milho e Sorgo, Caixa Postal 151, CEP 35701-970 Sete Lagoas, MG. E-mail: ramon@cnpms.embrapa.br

\section{Introdução}

Nos locais onde se pratica agricultura intensivamente ocorrem modificações na população de plantas espontâneas, passando a predominar as espécies que melhor se adaptam às atuais condições químicas, físicas e biológicas do solo. 
Em solos degradados, é de se esperar que predominem espécies mais resistentes às condições de estresse, que produzam pouca biomassa e absorvam menor quantidade de nutrientes. O mata-pasto (Cassia occidentalis) é um exemplo de espécie que passa a predominar em pastagens a partir do momento em que o solo é degradado (Alvarenga et al., 1996). A presença de espécies de maior resistência e rusticidade tendem a dificultar o uso e manejo do solo pelos agricultores, levando-os, em muitos casos, a adotarem a prática da queimada, acentuando o processo de degradação do solo.

Quando o objetivo é a melhoria da qualidade do solo, espera-se encontrar maior número de espécies, mais sensíveis às condições de estresse, que produzam mais biomassa, absorvam mais nutrientes e possam ser manejadas mais facilmente pelos agricultores.

O uso de plantas de cobertura para controlar a população de plantas espontâneas é prática tradicional. Um dos efeitos promovidos pelas coberturas é a ação alelopática, sendo o efeito mais ou menos específico. Cada planta, tanto em crescimento vegetativo quanto em processo de decomposição, exerce inibição específica sobre outras espécies, espontâneas ou cultivadas (Overland, 1966). Segundo Lorenzi (1984), a mucuna-preta (Mucuna aterrima) exerce forte e persistente ação inibitória sobre a tiririca (Cyperus rotundus) e o picão-preto (Bidens pilosa). Aos 120 dias após a emergência da mucuna-preta, Medeiros (1989) não verificou presença de outras espécies, atribuindo isto a efeitos alelopáticos. $\mathrm{O}$ feijão-de-porco (Canavalia ensiformes) exerce ação alelopática, principalmente sobre a tiririca (Neme et al., 1954; Neme, 1960; Magalhães \& Franco, 1960, 1962; Magalhães, 1964).

Outros efeitos das plantas de cobertura sobre as plantas espontâneas são a barreira física e a competição por água, luz, oxigênio e nutrientes. Trabalhos realizados nas Filipinas, citados por Altieri et al. (1978), apontaram excelente controle de plantas espontâneas pela associação de milho (Zea mays) com feijão-mungo (Phaseolus mungo), que é uma leguminosa de rápido desenvolvimento e ciclo curto. O consórcio entre girassol (Helianthus annuus) e feijoeiro (Phaseolus vulgaris) reduziu em 38 e $22 \%$ a massa seca de plantas espontâneas, em relação, respectivamente, ao cultivo solteiro de feijoeiro e gi- rassol (Machado, 1983). Akobundu \& Polku (1984), citados por Reijntjes et al. (1994), observaram que, em dezenove semanas, a mucuna (Mucuna utilis) conseguiu cobrir completamente uma área infestada por capim-sapé (Imperata brasiliensis). Além dessas características, a utilização de plantas de cobertura promove melhorias na qualidade do solo, podendo favorecer plantas espontâneas com maior capacidade de ciclagem de nutrientes e produção de biomassa.

O objetivo deste trabalho foi avaliar as modificações na população de plantas espontâneas por leguminosas usadas como adubos verdes.

\section{Material e Métodos}

O experimento foi realizado em Sete Lagoas, MG, na Embrapa-Centro Nacional de Pesquisa de Milho e Sorgo, localizada a $19^{\circ} 25^{\prime}$ de latitude Sul e $44^{\circ} 15^{\prime}$ de longitude Oeste, e altitude de $732 \mathrm{~m}$. O clima é do tipo Aw (tropical estacional de savana) na classificação de Köppen. A área experimental era de $600 \mathrm{~m}^{2}$, localizada numa encosta, em um Latossolo Vermelho distrófico típico, A moderado, textura argila, fase cerrado subcaducifólio, relevo suave ondulado. Algumas características químicas e físicas, determinadas segundo Embrapa (1979), de uma amostra composta do solo, coletada na área antes da instalação do experimento, estão apresentadas na Tabela 1 .

As características climáticas do local, durante o período experimental, de acordo com os dados obtidos na estação meteorológica da Embrapa-Centro Nacional de Pesquisa de Milho e Sorgo, estão apresentadas na Figura 1.

$\mathrm{O}$ experimento foi realizado nos anos agrícolas de 1995/96 e 1996/97 e consistiu de seis tratamentos distribuídos em blocos casualizados, com quatro repetições. Foram utilizadas cinco espécies de leguminosa como plantas de cobertura: feijão-de-porco (Canavalia ensiformes), feijão-bravo-do-ceará (Canavalia brasiliensis), mucuna-preta (Mucuna aterrima), lab-lab (Dolichos lablab) e guandu (Cajanus cajan). Houve também um tratamento testemunha, o qual permaneceu em pousio após o preparo do solo, havendo crescimento das plantas espontâneas.

Após o preparo do solo com grade aradora mecânica de 18 discos de 24" e niveladora leve de 36 discos de 18", as leguminosas foram semeadas manualmente em sulcos espaçados de $0,5 \mathrm{~m}$. A quantidade de sementes por metro linear variou conforme a espécie, utilizando-se maior número de sementes para posterior desbaste. Após a emergência das plântulas, efetuou-se desbaste, de forma que o estande inicial das espécies fosse: cinco plantas por metro 
linear de feijão-de-porco, feijão-bravo-do-ceará e mucunapreta, seis plantas por metro linear para o lab-lab e sete para o guandu.

Nas parcelas medindo $5 \times 5 \mathrm{~m}$, as leguminosas foram semeadas em novembro de 1995 e em novembro de 1996, sem adubação, e ficaram vegetando até completarem o ciclo.

Somente no ano agrícola 1996/97 os tratamentos foram avaliados. As épocas de amostragens se basearam no crescimento das leguminosas de cobertura sendo o tratamento testemunha igualmente amostrado nessas épocas. Neste segundo ciclo, avaliou-se a cobertura proporcionada ao solo e a produtividade de massa seca da parte aérea das plantas. A cobertura proporcionada ao solo foi avaliada aos 28, 56 e 84 dias após a emergência das leguminosas, separando-se a cobertura proporcionada pelas leguminosas daquela da cobertura proporcionada pelas plantas espontâneas. O método utilizado foi o do número de interseções (Alvarenga, 1993), o qual consiste na colocação de um quadrado de madeira com uma rede de barbantes espaçados regularmente, sobre a área em que se quer determinar a cobertura. A interseção entre dois barbantes perpendiculares define um ponto e representa uma área, conforme o espaçamento adotado. Conta-se, então, o número de interseções que estão sobre a vegetação. O somatório desses pontos, que significa o somatório das áreas que esses pontos representam, em relação à área total dos pontos

Tabela 1. Resultados das análises químicas e físicas de amostras do Latossolo Vermelho coletadas antes da instalação do experimento.

\begin{tabular}{|c|c|c|}
\hline \multirow[t]{2}{*}{ Característica do solo } & \multicolumn{2}{|c|}{$\begin{array}{c}\text { Profundidade } \\
\text { de amostragem }(\mathrm{cm})\end{array}$} \\
\hline & $0-20$ & $20-40$ \\
\hline pH (água) & 5,70 & 5,50 \\
\hline $\mathrm{pH}(\mathrm{KCl})$ & 5,28 & 4,85 \\
\hline$\Delta \mathrm{pH}$ & $-0,42$ & $-0,65$ \\
\hline $\mathrm{P}\left(\mathrm{mg} \mathrm{dm}^{-3}\right)$ & 12 & 7 \\
\hline M.O. $\left(\mathrm{mg} \mathrm{g}^{-1}\right)$ & 33,00 & 26,60 \\
\hline $\mathrm{Al}^{3+}\left(\mathrm{cmol}_{\mathrm{c}} \mathrm{dm}^{-3}\right)$ & 0,0 & 0,0 \\
\hline $\mathrm{H}+\mathrm{Al}\left(\mathrm{cmol}_{\mathrm{c}} \mathrm{dm}^{-3}\right)$ & 3,42 & 3,78 \\
\hline $\mathrm{Ca}^{2+}\left(\mathrm{cmol}_{\mathrm{c}} \mathrm{dm}^{-3}\right)$ & 5,01 & 3,01 \\
\hline $\mathrm{Mg}^{2+}\left(\mathrm{cmol}_{\mathrm{c}} \mathrm{dm}^{-3}\right)$ & 0,70 & 0,43 \\
\hline $\mathrm{K}^{+}\left(\mathrm{cmol}_{\mathrm{c}} \mathrm{dm}^{-3}\right)$ & 0,19 & 0,08 \\
\hline $\mathrm{S}\left(\mathrm{cmol}_{\mathrm{c}} \mathrm{dm}^{-3}\right)$ & 5,90 & 3,52 \\
\hline $\mathrm{m}(\%)$ & 0,0 & 0,0 \\
\hline $\mathrm{V}(\%)$ & 63,30 & 48,25 \\
\hline Equivalente de umidade (\%) & 30,09 & 30,20 \\
\hline Argila dispersa em água $\left(\mathrm{g} \mathrm{kg}^{-1}\right)$ & 260 & 280 \\
\hline Areia $\left(\mathrm{g} \mathrm{kg}^{-1}\right)$ & 180 & 150 \\
\hline Silte $\left(\mathrm{g} \mathrm{kg}^{-1}\right)$ & 320 & 250 \\
\hline Argila $\left(\mathrm{g} \mathrm{kg}^{-1}\right)$ & 500 & 600 \\
\hline Classe textural & Argilosa & Muito argilosa \\
\hline
\end{tabular}

do conjunto, fornece a porcentagem de cobertura do solo. Um quadro de madeira de $0,5 \mathrm{~m}$ de lado $\left(0,25 \mathrm{~m}^{2}\right)$ contendo uma rede de barbante com malha de $0,05 \mathrm{~m}$ foi lançado, por quatro vezes, em cada parcela.

Aos 90 dias após a emergência das leguminosas amostrou-se a parte aérea das plantas em quatro áreas de $0,25 \mathrm{~m}^{2}$ de cada parcela. As leguminosas e as plantas espontâneas foram cortadas à altura do colo, separadas, identificadas e acondicionadas em sacolas de papel, para posterior determinação da produtividade de matéria seca. A massa da matéria seca foi obtida após a secagem das amostras em estufa com circulação de ar forçada, a $65^{\circ} \mathrm{C}$, por 72 horas.

Em agosto de 1997, quando as leguminosas mais tardias estavam em final de ciclo (255 dias após a emergência das leguminosas), realizou-se uma avaliação visual da ocorrência das plantas espontâneas adotando-se o seguinte critério: estabeleceu-se uma escala de notas de 0 a 10 , na qual o valor 10 foi atribuído à maior ocorrência de plantas espontâneas, que foram as parcelas-testemunhas, e o
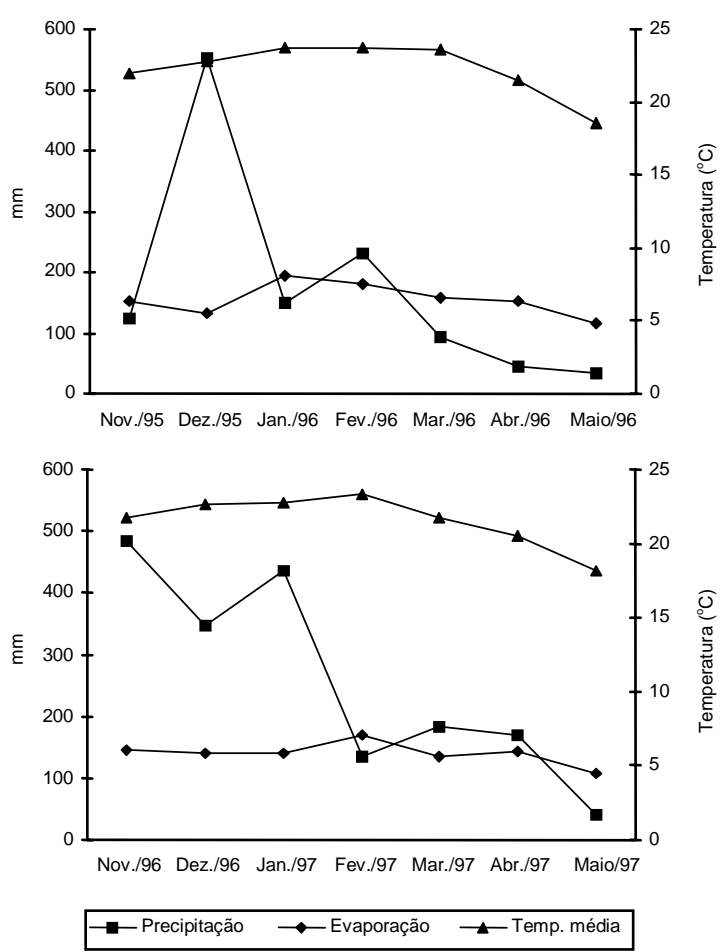

Figura 1. Médias mensais de precipitação $(\square, \mathrm{mm})$, evaporação $(\bullet, \mathrm{mm})$ e temperatura média $\left(\boldsymbol{\Lambda},{ }^{\circ} \mathrm{C}\right)$, observadas no período de novembro de 1995 a maio de 1996 e de novembro de 1996 a maio de 1997.

Pesq. agropec. bras., Brasília, v. 36, n. 11, p. 1355-1362, nov. 2001 
valor 0 , à ausência de plantas espontâneas. Observandose em diferentes posições, atribuíram-se três notas a cada parcela, calculando-se posteriormente a média das parcelas.

Os dados foram submetidos a análises de variância e as médias comparadas pelo teste de Student-NewmanKeuls a 5\%.

\section{Resultados e Discussão}

A mucuna-preta destacou-se das demais quanto à capacidade de recobrir o solo e abafar as plantas espontâneas (Tabela 2). Inicialmente, a sua taxa de cobertura foi igual à que foi apresentada pelo feijãode-porco e pelo feijão-bravo-do-ceará, e superior às outras espécies. Nas demais avaliações, aos 56 e 84 dias, ela se destacou com taxa de cobertura significativamente superior às outras espécies.

O crescimento indeterminado, rasteiro ou herbáceo prostrado dessas plantas, à exceção do guandu, conferem maior capacidade aos seus ramos e folhas de se distribuírem melhor e mais próximo do solo. Por essa razão, há maior pressão de controle sobre as plantas espontâneas, uma vez que apresentam maior capacidade de abafamento e agressividade, e diminui a sua população, por causa da competição por fatores de crescimento, especialmente luz. A barreira física exercida por plantas de cobertura é destacada por pesquisadores como importante maneira de redução da população de plantas espontâneas (Altieri et al., 1978; Machado, 1983; Reijntjes et al., 1994). Como resultado desse comportamento, a mucuna foi a espécie com maior pressão de abafamento sobre as plantas espontâneas pois foi capaz de eliminar essa concorrência já a partir dos 56 dias, o que não se observou com a mesma intensidade nas demais espécies de plantas de cobertura. Este potencial da mucuna em reduzir a população de plantas espontâneas é reconhecido na literatura. Brandão (1940) destaca a agressividade desta espécie como a principal característica na supressão de invasoras. Por outro lado, Lorenzi (1984) e Medeiros (1989) destacam o seu efeito alelopático, que inibe o crescimento de outras espécies, e prevalece desde o início do ciclo até o seu final.

O feijão-de-porco apresentou crescimento inicial rápido e ciclo mais curto entre as espécies testadas. Embora tenha exercido efeito de abafamento sobre as plantas espontâneas no início do ciclo, na terceira época de avaliação, 84 dias da emergência, já apresentava sinais de início de senescência, com diminuição na biomassa, ressecamento e queda de folhas mais baixas e, conseqüentemente, redução na cobertura proporcionada ao solo. Nessas condições, propiciou a queda da pressão de abafamento e o surgimento e o crescimento das plantas espontâneas. Ainda assim, seus efeitos foram semelhantes aos do feijão-bravo-do-ceará e superiores aos do lab-lab e do guandu.

O feijão-bravo-do-ceará, depois do crescimento inicial lento, tornou-se agressivo, após seu estabelecimento, e foi capaz de abafar até mesmo as plantas espontâneas já estabelecidas, reprimindo-as.

O lab-lab ocupou uma posição intermediária entre o guandu e as demais plantas de cobertura quanto à capacidade de recobrimento do solo no início do ciclo, e foi a espécie com menor taxa de cobertura e a menos eficiente em abafar as plantas espontâneas ao final do período de avaliação. Não se esperava esse comportamento do lab-lab na segunda metade

Tabela 2. Porcentagem de cobertura do solo proporcionada pelas leguminosas (LEG) e espécies espontâneas (ESP), crescendo em Latossolo Vermelho (segundo ciclo, 1996/97)(1).

\begin{tabular}{|c|c|c|c|c|c|c|c|c|c|}
\hline \multirow[t]{3}{*}{ Tratamento } & \multicolumn{9}{|c|}{ Dias após a emergência } \\
\hline & \multicolumn{3}{|c|}{28} & \multicolumn{3}{|c|}{56} & \multicolumn{3}{|c|}{84} \\
\hline & LEG & ESP & Total & LEG & ESP & Total & LEG & ESP & Total \\
\hline Feijão-de-porco & $51,25 \mathrm{~A}$ & $25,50 \mathrm{C}$ & $76,75 \mathrm{~A}$ & $83,00 \mathrm{~B}$ & $14,00 \mathrm{D}$ & $97,00 \mathrm{AB}$ & $81,25 \mathrm{~B}$ & $11,50 \mathrm{D}$ & $92,75 \mathrm{AB}$ \\
\hline F. bravo-do-ceará & $35,25 \mathrm{AB}$ & $45,25 \mathrm{AB}$ & $80,50 \mathrm{~A}$ & $67,75 \mathrm{C}$ & $31,75 \mathrm{C}$ & $99,50 \mathrm{~A}$ & $84,00 \mathrm{~B}$ & $14,00 \mathrm{D}$ & $98,00 \mathrm{AB}$ \\
\hline Mucuna-preta & $51,00 \mathrm{~A}$ & $29,25 \mathrm{C}$ & $80,25 \mathrm{~A}$ & $99,75 \mathrm{~A}$ & $0,25 \mathrm{E}$ & $100,00 \mathrm{~A}$ & $100,00 \mathrm{~A}$ & $0,00 \mathrm{E}$ & $100,00 \mathrm{~A}$ \\
\hline Lab-lab & $30,75 \mathrm{~B}$ & $37,50 \mathrm{BC}$ & $68,25 \mathrm{~A}$ & $30,50 \mathrm{D}$ & $62,00 \mathrm{~B}$ & $92,50 \mathrm{AB}$ & $26,75 \mathrm{D}$ & $60,75 \mathrm{~B}$ & $87,50 \mathrm{BC}$ \\
\hline Guandu & $14,25 \mathrm{C}$ & $53,50 \mathrm{AB}$ & $67,75 \mathrm{~A}$ & $31,00 \mathrm{D}$ & $58,25 \mathrm{~B}$ & $89,25 \mathrm{~B}$ & $43,75 \mathrm{C}$ & $45,75 \mathrm{C}$ & $89,50 \mathrm{BC}$ \\
\hline Testemunha & - & $65,00 \mathrm{~A}$ & $65,00 \mathrm{~A}$ & - & $81,50 \mathrm{~A}$ & $81,50 \mathrm{C}$ & - & $85,25 \mathrm{~A}$ & $85,25 \mathrm{C}$ \\
\hline
\end{tabular}

${ }^{1}$ Médias seguidas pela mesma letra, na coluna, não diferem estatisticamente entre si, pelo teste de Student-Newman-Keuls, a 5\% de probabilidade. 
do período de estudo. Entretanto, nos dois anos considerados, observou-se que essa espécie sofria intenso ataque de insetos, especialmente da vaquinha (Diabrotica speciosa), que causava significativa perda de área foliar, o que certamente contribuiu negativamente para o seu desenvolvimento e desempenho, comprovado pela baixa taxa de cobertura do solo.

O guandu proporcionou a menor cobertura do solo aos 28 dias após a emergência e, conseqüentemente, nessa fase foi menos eficiente em promover o abafamento das plantas espontâneas. Aos 84 dias de crescimento, já apresentava taxa de cobertura de solo e de abafamento superior ao lab-lab. Esses resultados se devem, em parte, à característica de crescimento mais lento dessa espécie e ao seu hábito de crescimento arbustivo, que lhe confere menor agressividade na supressão das plantas espontâneas. No entanto, após seu crescimento, talvez por causa do sombreamento provocado, exerceu ação repressiva sobre as plantas espontâneas já estabelecidas.

No tratamento-testemunha, com a ausência de plantas de cobertura e da pressão de competição exercida por elas, as plantas espontâneas atingiram os maiores valores, os quais foram significativamente superiores aos dos tratamentos com plantas de cobertura, nas duas últimas épocas de avaliação (Tabela 2). Por outro lado, em presença das plantas de cobertura, as plantas espontâneas tiveram um comportamento inverso, ou seja, elas foram as causadoras da maior taxa de cobertura naqueles tratamentos em que a leguminosa de cobertura apresentou menor taxa. No tratamento com mucuna-preta, a porcentagem de cobertura das plantas espontâneas foi menor que nos demais tratamentos, nas três épocas avaliadas e não se diferenciou significativamente do tratamento com feijão-de-porco, apenas aos 28 dias após a emergência das leguminosas. No tratamento com lab-lab, a cobertura proporcionada pelas plantas espontâneas foi maior que nas demais leguminosas, não se diferenciando significativamente dos tratamentos com guandu e feijão-bravo-do-ceará aos 28 dias após a emergência e do guandu aos 56 dias após a emergência.

Os tratamentos apresentaram resultados significativamente diferentes nas duas últimas épocas de avaliação em relação à cobertura total do solo. $\mathrm{Na}$ primeira, como as plantas ainda estavam em es- tádio de estabelecimento, parece que a competição foi pouco intensa. Já a partir da segunda época, a pressão de competição se pronunciou, havendo maior cobertura naqueles tratamentos em que a leguminosa de cobertura foi mais agressiva, recobrindo maior porcentagem do solo, conforme já discutido. Uma análise da dinâmica dessa competição demonstra que a mucuna-preta, o feijão-de-porco e o feijão-bravo-do-ceará foram as leguminosas com maior capacidade de suprimir as plantas espontâneas já na segunda avaliação. Resultados semelhantes foram observados por Neme et al. (1954), Neme (1960), Magalhães \& Franco (1960, 1962), Magalhães (1964), Lorenzi (1984) e Medeiros (1989). O guandu só mostrou esse potencial na terceira época, e o lab-lab não apresentou essa característica, talvez como conseqüência dos problemas de ataque de pragas sofrido, conforme salientado.

$\mathrm{Na}$ avaliação visual da ocorrência das plantas espontâneas, realizada em agosto de 1997, 255 dias após a emergências das plantas de cobertura, os tratamentos com mucuna-preta, com feijão-bravo-doceará e com guandu apresentaram menor incidência de plantas espontâneas que os tratamentos com feijão-de-porco, com lab-lab e na testemunha (Figura 2). Estes resultados se deveram principalmente à duração do ciclo dessas plantas e à persistência da

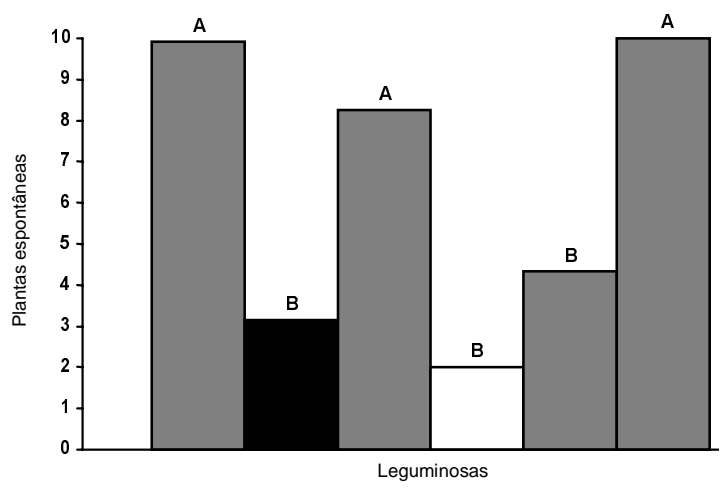

Figura 2. Ocorrência de plantas espontâneas aos 255 dias após a emergência das leguminosas de cobertura: feijãode-porco $(\square)$; feijão-bravo-do-ceará $(\square)$; lab-lab ( $\square$ ); mucuna-preta ( $\square$ ); guandu ( $\square$ ); testemunha ( $\square$ ). Mesma letra sobre barras diferentes indica ausência de diferença estatística entre elas, pelo teste de Student-Newman-Keuls, a $5 \%$ de probabilidade. Em relação às plantas espontâneas os valores referem-se a notas (0: ausência e 10: maior proporção de plantas espontâneas). 
biomassa produzida por elas, pois, segundo Overland (1966), as plantas exercem inibição sobre outras, tanto durante o período de crescimento quanto durante o processo de decomposição. O feijão-de-porco, que iniciou o florescimento aos 74 dias após a emergência, nesta época, já havia completado o seu ciclo, e parte de sua biomassa se encontrava seca, sobre o solo, e parcialmente decomposta, sendo que as folhas já haviam sido totalmente mineralizadas. No caso do lab-lab, que floresceu aos 112 dias, acredita-se que o ataque de insetos tenha sido um importante fator a contribuir para esse resultado, pois a menor área foliar favoreceu o crescimento das plantas espontâneas. No lab-lab também se observou intensa mineralização das folhas. O feijão-bravo-do-ceará e a mucuna iniciaram o período de florescimento aos 149 e 120 dias, respectivamente, e vegetavam mantendo a cobertura do solo, estando verdes na parte superior e apresentando hastes e folhas secas e semi- decompostas no interior da massa, num micro-ambiente um pouco úmido. O guandu, que iniciou o florescimento aos 138 dias, apresentava-se verde, com vagens maduras e a superfície do solo recoberta por folhas secas, sem evidências de decomposição. Acredita-se que, em virtude do crescimento arbustivo dessa espécie, há maior facilidade de circulação de ar, e, conseqüentemente, perdas de água por evaporação do solo, o que cria um ambiente menos favorável à decomposição e também ao crescimento das espontâneas, especialmente aquelas com sistema radicular superficial.

O feijão-bravo-do-ceará, seguido da mucuna-preta e do feijão-de-porco, foram as leguminosas com maiores produtividades de matéria seca, significativamente superiores à do guandu, que ocupou uma posição intermediária, e ao lab-lab, que foi a espécie que apresentou menor produção de biomassa aérea (Tabela 3). Esses resultados são grandemente depen-

Tabela 3. Produção de matéria seca da parte aérea $\left(\mathrm{kg} \mathrm{ha}^{-1}\right)$ das leguminosas e das espécies espontâneas aos 90 dias após a emergência ${ }^{(1)}$.

\begin{tabular}{|c|c|c|c|c|c|c|}
\hline \multirow[t]{2}{*}{ Cobertura viva } & \multicolumn{6}{|c|}{ Matéria seca da parte aérea (média do tratamento) } \\
\hline & $\mathrm{FdP}$ & $\mathrm{FbC}$ & $\mathrm{Lab}$ & Muc & Gua & Tes \\
\hline Leguminosa & $5.371 \mathrm{~A}$ & $7.251 \mathrm{~A}$ & $736 \mathrm{C}$ & $6.987 \mathrm{~A}$ & $2.867 \mathrm{~B}$ & - \\
\hline Espécies espontâneas & $1.035 \mathrm{CD}$ & 2.334B & $1.951 \mathrm{BC}$ & $166 \mathrm{D}$ & $2.901 \mathrm{AB}$ & $3.740 \mathrm{~A}$ \\
\hline Bidens pilosD & 105 & 624 & 228 & 25 & 384 & 247 \\
\hline BlDinvilleDlDifoliD & - & 144 & - & - & 13 & 78 \\
\hline BrDchiDriDplDhtDgineD & 12 & 59 & 29 & - & 40 & - \\
\hline Cenchrus echinDus & 79 & 195 & 265 & 11 & 942 & 1298 \\
\hline Chenopodium Dbum & - & - & 20 & - & - & - \\
\hline Cynodon dDetylon & 183 & 251 & 105 & 4 & 320 & 76 \\
\hline Cyperus rotundus & 22 & - & 46 & - & 21 & 20 \\
\hline CommelinDbenghDensis & 93 & 52 & 192 & 81 & 144 & 262 \\
\hline Croton glDndulosus & 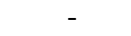 & 9 & - & - & 31 & - \\
\hline DigitDriDhorizontDis & 87 & 72 & 147 & - & 172 & 206 \\
\hline Eleusine indicD & - & - & 40 & - & 76 & 15 \\
\hline EmiliDsonchifoliD & - & - & 9 & - & 20 & - \\
\hline EuphorbiDheterophyllD & - & - & - & - & - & 10 \\
\hline MelDhpodium perfoliDum & 45 & 703 & 401 & 22 & 113 & 437 \\
\hline NicDndrDphysDoides & 18 & - & - & - & - & 25 \\
\hline PDnicum mDximum & 307 & 223 & 277 & - & 428 & 890 \\
\hline PortulDcDolerDeeD & - & - & - & - & - & 15 \\
\hline RDphDhus rDphDhistrum & 33 & - & - & - & - & - \\
\hline RichDrdiDbrDsiliensis & 41 & - & 95 & 1 & 139 & 120 \\
\hline SidDglDziovii & - & - & 22 & - & - & - \\
\hline SpermDeoce lDifolD & 10 & 2 & 75 & - & 58 & 41 \\
\hline Outras & - & - & - & 22 & - & - \\
\hline
\end{tabular}

${ }^{(1)}$ Médias seguidas pela mesma letra, na linha, não diferem estatisticamente entre si, pelo teste de Student-Newman-Keuls, a 5\% de probabilidade; FdP: feijãode-porco; FbC: feijão-bravo-do-ceará; Lab: lab-lab; Muc: mucuna-preta; Gua: guandu; Tes: testemunha. 
dentes da velocidade de crescimento das espécies conforme já foi discutido, de tal forma que aquelas de crescimento mais precoce e ou agressivas proporcionaram uma biomassa mais abundante aos noventa dias após emergência. Quanto à biomassa aérea produzida pelas plantas espontâneas, observa-se um comportamento semelhante ao verificado com relação à taxa de cobertura de solo, ou seja, no tratamento em que a planta de cobertura cresceu mais, e a uma maior taxa, houve menor biomassa das plantas espontâneas. Dessa maneira, a produtividade de matéria seca das plantas espontâneas na presença de mucuna-preta foi menor que nos demais tratamentos com leguminosas, e a maior produtividade foi a da testemunha.

A diminuição na produtividade de matéria seca das plantas espontâneas na presença das leguminosas de cobertura, como já discutido, deveu-se aos efeitos de concorrência entre elas, ou seja, abafamento, competição por nutrientes, água, luminosidade e oxigênio e, possivelmente, também aos efeitos alelopáticos provocados pelas leguminosas cultivadas sobre as plantas espontâneas. A importância dessa competição, especialmente a alelopática, como mecanismos de suprimir plantas espontâneas, é destacada por vários pesquisadores (Overland, 1966; Lorenzi, 1984; Medeiros, 1989).

Houve uma dinâmica de sucessão de espécies nas parcelas cultivadas com as leguminosas de cobertura. Algumas plantas espontâneas que não ocorriam na testemunha passaram a ocorrer nos tratamentos com leguminosas, assim como outras espécies presentes na parcela-testemunha não estavam presentes em alguns dos tratamentos com plantas de cobertura. Brachiaria plantaginea, Chenopodium album, Croton glandulosus, Emilia sonchifolia, Raphanus raphanistrum e Sida glaziovii foram espontâneas ausentes da parcela-testemunha que passaram a ser encontradas nos tratamentos com leguminosas. Por outro lado, Euphorbia heterophylla e Portulaca oleracea ocorreram na testemunha, e não ocorreram nos tratamentos com leguminosas (Tabela 3 ).

Em ordem decrescente de importância, em face da quantidade de biomassa produzida nos tratamentos, destacam-se algumas espécies, a saber: na testemunha, Cenchrus echinatus e Panicum maximum, que produziram, respectivamente, 1.298 e $890 \mathrm{~kg} \mathrm{ha}^{-1}$ de matéria seca, representando $58 \%$ da matéria seca produzida pela testemunha. Na testemunha houve maior diversidade de plantas espontâneas, como resultado da ausência da competição imposta pelas plantas de cobertura. No tratamento com feijão-bravo-do-ceará, Melanpodium perfoliatum e Bidens pilosa produziram, respectivamente, 703 e $624 \mathrm{~kg} \mathrm{ha}^{-1}$, o que representou $57 \%$ da produtividade de matéria seca das plantas espontâneas desse tratamento. No caso do guandu, as espontâneas Cenchrus echinatus, Panicum maximum, Bidens pilosa e Cynodon dactylon representaram 71\%. No lab-lab, as espécies Melanopodium perfoliatum, Panicum maximum, Cenchrus echinatus e Bidens pilosa produziram $60 \%$ da matéria seca total. No caso do feijão-de-porco, destacaram-se a Panicum maximum e a Cynodon dactylon, e na mucuna, a Commelina benghalensis foi a única espécie de destaque, apesar da baixa massa produzida. A mucuna-preta foi eficiente em reduzir ou eliminar a concorrência com as plantas espontâneas, o que pode ser atribuído à pressão de competição e aos efeitos alelopáticos, conforme descrito por diversos pesquisadores (Tabela 3). Lorenzi (1984) atribuiu este papel da mucuna ao forte e persistente efeito inibitório, em especial sobre as espécies Bidens pilosa (picão-preto) e Cyperus rotundus (tiririca). Medeiros (1989) destacou a presença dessa ação alelopática durante todo o ciclo da mucuna.

\section{Conclusões}

1. Entre as espécies estudadas, a mucuna-preta é a de maior potencial para recobrimento de solo e supressão de plantas espontâneas, e o lab-lab, a de menor potencial.

2. O uso de leguminosas para adubação verde promove modificações na dinâmica de sucessão das espécies espontâneas.

\section{Referências}

ALTIERI, M. A.; FRANCIS, C. A.; SCHOONHOVEN, A. V.; DOLL, J. D. A review of insect prevalence in maize (Zea mays L.) and bean (mhaseolus vulgaris L.) polycultural systems. Field Crops Research, Amsterdam, v. 1, p. $33-49,1978$.

ALVARENGA, R. C. Potencialidades de adubos verdes para conservação e recuperação de solos. Viçosa, MG: UFV, 1993. 112 p. Tese de Doutorado. 
ALVARENGA, R. C.; COSTA, L. M. da; MOURA FILHO, W.; REGAZZI, A. J. Crescimento de raízes de leguminosas em camadas de solo compactadas artificialmente. Revista Brasileira de Ciência do Solo, Campinas, v. 20, n. 2, p. 319-326, 1996.

BRANDÃO, S. Adubação verde. Revista Ceres, Viçosa, MG, v. 1, p. 483-495, 1940.

EMBRAPA. Serviço Nacional de Levantamento de Solos (Rio de Janeiro). Manual de métodos de análise de solo. Rio de Janeiro, 1979. $1 \mathrm{v}$

LORENZI, H. Inibição alelopática de plantas daninhas. In: FUNDAÇÃO CARGILL (Campinas, SP). Adubação verde no Brasil. Campinas: Fundação Cargill, 1984. p. 183-198.

MACHADO, C. M. N. Eficiência da consorciação de culturas na utilização da terra e no controle de plantas daninhas. Porto Alegre: UFRGS, 1983. 120 p. Dissertação de Mestrado.

MAGALHÃES, A. C. Efeito inibidor de extratos de plantas de feijão-de-porco sobre o desenvolvimento da tiririca. Bragantia, Campinas, v. 23, p. 29-34, 1964.

MAGALHÃES, A. C.; FRANCO, C. M. Efeito do extrato de nódulos de raízes de feijão-de-porco sobre o desenvolvimento de tubérculos de tiririca. In: SEMINÁRIO BRA-
SILEIRO DE HERBICIDAS E ERVAS DANINHAS, 4. 1960, Rio de Janeiro. Anais... Rio de Janeiro: Sociedade Brasileira de Plantas Daninhas, 1960. p. 59-63.

MAGALHÃES, A. C.; FRANCO, C. M. Toxicidade do feijão-de-porco sobre a tiririca. Bragantia, Campinas, v. 21, p. 53-58, 1962.

MEDEIROS, A. R. M. de. Determinação de potencialidades alelopáticas em agroecossistemas. Piracicaba: Esalq, 1989. 92 p. Tese de Doutorado.

NEME, N. A. Combate a tiririca. O Agronômico, Campinas, v. 12, p. 5-6, 1960.

NEME, N. A.; MIRANDA, H. S.; FORSTER, R. A ação da cultura do feijão-de-porco no combate a tiririca. In: CONGRESSO PAN-AMERICANO DE AGRONOMIA, 2., 1954, Piracicaba. Anais... Piracicaba: Esalq, 1954. p. 261-262.

OVERLAND, L. The role of allelopathic substances in the "smothes crop". American Journal of Botany, Columbus, v. 53, p. 423-432, 1966.

REIJNTJES, C.; HAVERKORT, B.; WATERS-BAYER, A. Agricultura para o futuro: uma introdução à agricultura sustentável e de baixo uso de insumos externos. Rio de Janeiro: Assessoria e Serviços a Projetos em Agricultura Alternativa, 1994. $324 \mathrm{p}$. 